\title{
Idiopathic subglottic stenosis: outcomes with or without the use of protective tracheostomy in single-stage cricotracheal resection
}

\author{
V. Cheung, G. Gelfand, S. McFadden, and J.D. Bosch. University of Calgary, Calgary AB.
}

\section{Objectives}

The primary objective of this study was to determine the effect of a protective tracheostomy on post-operative complications from a single-stage cricotracheal resection and reconstruction for idiopathic subglottic stenosis. The secondary purpose was to identify the rate of recurrent stenosis and functional results, and to characterize the post-operative course for these resections.

\section{Background}

Idiopathic subglottic stenosis (idiopathic laryngotracheal stenosis) is a rare inflammatory condition of unknown etiology affecting the upper airway. It is a diagnosis of exclusion, after ruling out traumatic, infectious, immunologic and congenital causes. Idiopathic subglottic stenosis can be successfully treated with singlestage resection and reconstruction. Practice varies on the use of a temporary protective tracheostomy at the time of surgery to mitigate the risk of airway obstruction from postoperative laryngeal edema. Alternatives include treatment of edema with steroids and diuresis post-extubation. Benefits of a protective tracheostomy, particularly with cricotracheal resections, include airway protection and improved secretion clearance, but with potential complications associated with the tracheostomy.

\section{Methods}

We conducted a retrospective single-institution cohort study comparing patients with or without a protective tracheostomy in cricotracheal resections. Patients who underwent surgical resection and reconstruction for idiopathic subglottic stenosis from January 1, 1994 to August 31, 2015 at Foothills Medical Centre were reviewed. Tracheal resections were excluded. For the cricotracheal resections, no protective tracheostomy was utilized prior to January 2010; subsequently, protective tracheostomy was routinely used, due to a change in practice by the surgeons. The procedure included resection of the proximal trachea, anterior half of the cricoid cartilage, excision of the mucosa and submucosa on the posterior cricoid plate and anastomosis with a posterior membranous tracheal wall flap. Follow up was one year. Data was collected through retrospective chart review. Chi-square test and student's ttest were used for statistical analysis, and performed using SPSS Statistics version 19.0.
Fifty-one patients were identified who underwent a surgical resection and reconstruction for idiopathic subglottic stenosis. Thirteen patients had a tracheal resection and primary anastomosis, and were excluded. All 13 cases were performed without tracheostomy and 9 were extubated successfully in the operating room. A total of 38 patients had a cricotracheal resection and primary anastomosis, and were included in the study and analysis. The initial 11 , prior to January 2010 , did not have a protective tracheostomy; the subsequent $27 \mathrm{did}$. All procedures were performed by the same surgical team consisting of thoracic surgery and otolaryngology. Both groups were similar in characteristics (Table 1).

\begin{tabular}{|c|c|c|}
\hline & $\begin{array}{l}\text { No protective } \\
\text { tracheostomy } \\
(\mathrm{N}=11)\end{array}$ & $\begin{array}{c}\text { Protective } \\
\text { tracheostomy } \\
(\mathrm{N}=27)\end{array}$ \\
\hline Age - years & 52 & 48 \\
\hline \multicolumn{3}{|l|}{ Gender } \\
\hline Male & $1(9 \%)$ & 0 \\
\hline Female & $10(91 \%)$ & $27(100 \%)$ \\
\hline Obese (BMI>30) & $2(18 \%)$ & $11(41 \%)$ \\
\hline Smoker & $1(9 \%)$ & $4(15 \%)$ \\
\hline GERD & $5(45 \%)$ & $20(74 \%)$ \\
\hline Prior intubation & $8(73 \%)$ & $21(78 \%)$ \\
\hline Prior extended intubation & 0 & $1(4 \%)$ \\
\hline ANA or ANCA positive & 0 & $1(4 \%)$ \\
\hline Number of endoscopic treatments before surgery & 2.9 & 4.5 \\
\hline Length of stenosis (mm) & 15.2 & 13.8 \\
\hline Distance of stenosis from vocal cords $(\mathrm{mm})$ & 17.9 & 15.8 \\
\hline Number of tracheal rings resected & 2.7 & 2.6 \\
\hline
\end{tabular}

There was no increase in the rate of overall complications, and a decrease in the rate of airway-related complications by using a protective tracheostomy $(15 \%$ vs $55 \%, p=0.01)$ (Table 2$)$. The main tracheostomy-specific complication was wound infection (15\%). Overall hospital stay was not prolonged with tracheostomy. Length of time on a ventilator ( 1.1 vs 2.8 days, $p=0.01$ ) and ICU stay ( 1.2 vs 3.8 days, $\mathrm{p}=0.001)$ were shorter in the group with a protective tracheostomy, an important consideration in terms of overall cost. In our series, cricotracheal resection without tracheostomy was associated with a higher rate of restenosis, early granulation and earlier recurrence (Table 3). As expected, there was a higher use of steroids to treat edema in this group.

Conclusion

The use of a protective tracheostomy is associated with fewer post-operative airway complications, a shorter duration on the ventilator and a shorter ICU stay. It is a safe approach in the single-stage cricotracheal resection and reconstruction.

Reference: Wang H, Wright CD, Wain JC, et al. Idiopathic Subglottic Stenosis: Factors Affecting Outcome After SingleStage Repair. Ann Thorac Surg 2015;100:1804-11.

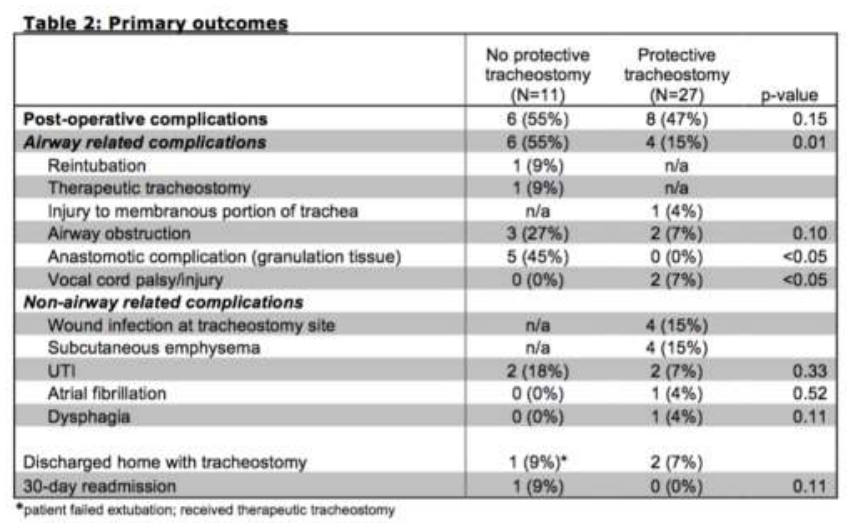

One-year follow up was $81 \%$ and $100 \%$ in the tracheostomy and nontracheostomy groups respectively. All the patients had subjectively normal swallowing and good voice, with the expected changes of decreased pitch and decreased ability to project.

T.able 3: Secondary outcomes
\begin{tabular}{|l|ccr|}
\hline & $\begin{array}{c}\text { No protective } \\
\text { tracheostomy }\end{array}$ & $\begin{array}{c}\text { Protective } \\
\text { tracheostomy }\end{array}$ & p-value \\
\hline Recurrence & $\begin{array}{c}(\mathrm{N}=9) \\
(\mathrm{N}=23)\end{array}$ & 0.01 \\
\hline Restenosis & $4(36 \%)$ & $1(4 \%)$ & $<0.05$ \\
\hline Time to restenosis -months & 2 & 48 & \\
\hline Perioperative results & $(\mathrm{N}=11)$ & $(\mathrm{N}=27)$ & \\
\hline Hospital length of stay & 10.1 & 11.7 & 0.19 \\
\hline ICU length of stay & 3.8 & 1.3 & $<0.05$ \\
\hline Days to extubation & 2.6 & $\mathrm{n} / \mathrm{a}$ & \\
\hline Days to decannulation & $\mathrm{n} / \mathrm{a}$ & 10.6 & \\
\hline Days on ventlator & 2.8 & 1.1 & 0.01 \\
\hline Operative time - minutes & 250 & 266 & 0.23 \\
\hline Use of post-operative steroids & $7(64 \%)$ & $6(22 \%)$ & 0.02 \\
\hline
\end{tabular}

This study was limited by the small sample size and retrospective design. The learning curve with cricotracheal resections may have affected the results, with higher recurrence rate in the non-tracheostomy group potentially attributable to the early operative experience with the procedure.

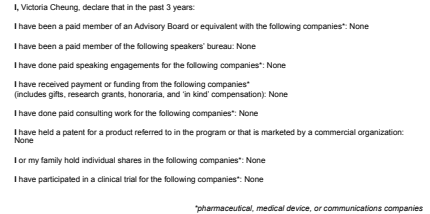

